\title{
Treatment of systemic sclerosis: potential role for stem cell transplantation
}

This article was published in the following Dove Press journal:

Stem Cells and Cloning:Advances and Applications

17 November 2009

Number of times this article has been viewed

\section{Wen Xiong Chris T Derk \\ Division of Rheumatology, Thomas Jefferson University, Philadelphia,} PA, 19107, USA
Correspondence: Chris T Derk Associate Professor of Medicine, Division of Rheumatology, Thomas Jefferson University, 613 Curtis Bldg, 1015 Walnut Street, Philadelphia, PA 19107, USA

$\mathrm{Tel}+\mid$ 2I5-955-1410

Fax + I 215-923-7885

Email chris.derk@jefferson.edu
Abstract: Hematopoietic stem cell transplantation may "reset" the immune reconstitution and induce self tolerance of autoreactive lymphocytes, and has been explored in the treatments for systemic sclerosis. Phase I/II trials have shown a satisfactory risk benefit ratio. The true benefit will be identified by two ongoing prospective, randomized phase III trials. Multipotent mesenchymal stromal cells (MSCs) possess antiproliferative, anti-inflammatory, and immunosuppressive properties. The use of MSCs has showed successful responses in patients with severe steroid-resistant acute graft versus host disease in phase II trials, and may be a potentially promising option for patients with systemic sclerosis.

Keywords: scleroderma, systemic sclerosis, treatment, stem cells, transplant

\section{Introduction}

Systemic sclerosis (SSc) is a chronic autoimmune connective tissue disorder manifested by excess synthesis and deposition of collagen (both type I and III) in skin and visceral organs, vascular abnormalities and autoimmunity. ${ }^{1}$ Physically debilitating, scleroderma is associated with a 5- to 8-fold increase in mortality over that of the general population. ${ }^{2}$ High skin score, pulmonary, renal, or cardiac involvement is associated with a higher mortality of $40 \%$ to $50 \%$ within 5 years. ${ }^{3-7}$ The pathogenesis of SSc is extremely complex, which involves interactions between endothelial cells, epithelium, immunological mediators, lymphocytes, and fibroblasts. The functional alterations in these cells result in three characteristic changes in SSc: dysregulated vascular remodeling and, ultimately, vasculopathy with obliteration of the lumen of small arteries and arterioles; humoral and cellular immunologic abnormalities; and progressive cutaneous and visceral fibrosis. ${ }^{8}$ Endothelial cell injury is an early and probably initiating event, although the precise etiology remains unclear. Endothelin-1 (ET-1) is believed to be a potent mediator of vasculopathy, and therefore represents a potentially therapeutic target. ${ }^{9}$ To date, there is no single therapeutic agent proven to be universally effective, although several studies have shown that cyclophosphamide may improve skin thickening and lung fibrosis, and the efficacy of mycophenolate mofetil in scleroderma-related interstitial lung disease has also been described. ${ }^{10-12}$ The European League Against Rheumatism (EULAR) Scleroderma Trials and Research group (EUSTAR) published a set of core recommendations for treatment of SSc based on clinical research evidence in published literature, expert opinion, and clinical experience. The EULAR guidelines recommend assessing the patient for organ systems involved, and on the basis of this assessment, suggest using cyclophosphamide for lung submit your manuscript | www.dovepress.com

Dovepress 
disease or methotrexate for skin disease. Mycophenolate mofetil and azathioprine are good alternative treatments for lung disease; methotrexate is the most appropriate treatment for scleroderma overlap condition. ${ }^{13}$ ET-1 antagonists and sildenafil are supported by randomized trials on scleroderma associated pulmonary hypertension and possibly digital ulcerations. Most recently, new drugs such as relaxin, pirfenidone, halofuginone, tyrosine kinase inhibitors, antiTGF-b antibodies, and histone deacetylase-7 inhibitor have been used as antifibrotic agents in the treatment of SSc, in some cases with promising results. ${ }^{14,15}$

Hematopoietic stem cell transplantation (HSCT) is a potential therapy for patients with severe and refractory autoimmune disease. It is proposed to possibly "reset" the immune system of the host. The recipient is prepared for the transplant by immunosuppressive treatment, usually by chemotherapy and/or radiation therapy, followed by the transfers of autologous hematopoietic cells (cell harvested from the recipient before patient conditioning) or allogeneic hematopoietic cells (cell harvested from donors rather than the recipient) to restore the host immune system. ${ }^{16}$ Preclinical studies have supported this rationale in two animal models. ${ }^{17}$ Case series of patients undergoing allogeneic HSCT for malignancy or aplastic anemia revealed long-term remission of coexistent autoimmune diseases. ${ }^{18}$ In 1996, the first case of a patient with an autoimmune disease who underwent autologous hematopoietic stem cell transplantation was reported. ${ }^{19}$ Since then, over 1000 patients with severe or organ-threatening autoimmune disease have been treated with hematopoietic stem cell transplantation, mostly through autologous stem cell transplantation, due to concerns about an increased risk of graft versus host disease (GVHD) associated with allogeneic grafting. The transplant-related mortality observed in severe SSc patients has decreased significantly over time from $17 \%$ early on to $8.7 \%$ more recently. ${ }^{20,21}$ Two prospective controlled trials of HSCT in SSc are ongoing. The Autologous Stem Cell Transplantation International Scleroderma (ASTIS) trial (www.astistrial. com) was launched in 2001 by the European Group for Blood and Marrow Transplantation (EBMT)/EULAR scleroderma study group, to compare the efficacy and safety of high dose immunoablation and HSCT with intravenous pulse therapy cyclophosphamide for the treatment of patients with severe SSc. ${ }^{22}$ The Scleroderma: Cyclophosphamide or Transplantation (SCOT) trial (www.sclerodermatrial. org) is sponsored by the US National Institutes of Health (NIH), similarly to compare the efficacy and safety of hematopoietic cell transplantation following high-dose immunosuppressive therapy with monthly intravenous pulse cyclophosphamide.

In the past several years, multipotent mesenchymal stromal cells, also referred to as mesenchymal stem cells (MSCs) have attracted attention in the treatment of autoimmune diseases. Their availability, low toxicity, as well as antiproliferative, anti-inflammatory, and immunosuppressive properties have been explored in animal models and in patients with severe GVHD, and MSCs may be a potential treatment option in patients with SSc, although data on the results of using MSCs in human autoimmune disease are scarce.

\section{HSCT in systemic sclerosis}

\section{Rationale for HSCT}

Animal models with autoimmune diseases provided the rationale for HSCT. Investigations on hematopoietic chimeric rodents' strains have revealed the important role of the hematopoietic system. The determinant of the susceptibility or resistance to various autoimmune diseases in these chimeric animals relies on the genotype of the bone marrow, which led to the hypothesis that the underlying defect resides in the hematopoietic stem cell. ${ }^{23,24}$ The majority of preclinical experiments supported the rationale for HSCT with two animal models, adjuvant arthritis and experimental allergic encephalomyelitis (EAE) induced in Buffalo rats. In these strains, adjuvant arthritis is manifested as a chronic, progressive systemic polyarthritis which mostly resembles human rheumatoid arthritis (RA); experimental allergic encephalomyelitis induced in Buffalo rats is manifested as a chronic, remitting/relapsing form of encephalomyelitis resembling multiple sclerosis (MS). In nearly all rats with adjuvant arthritis and $70 \%$ of rats with EAE absence of spontaneous relapses was complete after autologous stem cell transplantations with total body irradiation. ${ }^{17}$ Autologous HSCT was most successful at early disease stage, no effect was observed at more advanced stages. The success of treatment also depends on how completely the autoantigen-specific activated T-lymphocytes and memory cells are eradicated with increased intensity of conditioning therapy or certain conditioning agents. ${ }^{25}$ The stronger lympho-myeloablative regimens, like high-dose total body irradiation (TBI) (9-10 Gy) results in better response to HSCT; however, high-dose TBI is associated with serious late carcinogenic events. ${ }^{23}$ In both adjuvant arthritis and EAE models in Buffalo rats, cyclophosphamide alone or busulfan alone at the highest tolerated doses were less effective than high-dose TBI. Combination of cyclophosphamide with lower dose (4 Gy) TBI and the 
combination of busulfan with cyclophosphamide were as effective as high-dose TBI. ${ }^{24}$

In comparison to autologous HSCT in animal models with EAE, allogeneic HSCT was found to be superior in terms of suppressing spontaneous relapse rates, $30 \%$ vs $5 \%$ respectively. ${ }^{26,27}$ This may suggest that allogeneic donor $\mathrm{T}$ cells eliminate autoreactive host lymphocytes, and may induce tolerance to autoimmune epitopes by deletion of autoreactive repertoires, and therefore, mediate a form of immunotherapy termed graft-versus-autoimmunity (GVA). ${ }^{28,29}$ Animal studies also demonstrate that resistance to autoimmune disease resides and can be transferred by hematopoietic stem cells. Engraftment of allogeneic stems cells could result in tolerance to donor antigens, permitting acceptance of donor-derived tissue without intensive immunosuppressive therapy. ${ }^{30}$ Thus animal studies support HSCT in autoimmune diseases with several potentially useful clinical strategies.

Although a putative GVA effect from allogeneic HSCT theoretically may be beneficial, the most significant toxicity of allogeneic HSCT is an immunologic reaction of donor cells against host tissues, a complication known GVHD, associated with significant morbidity and mortality. Most recently, several groups have used mini-conditioning with non-myeloablative or reduced-intensity conditioning in animal models, and human trials for allogeneic HSCT resulted in less GVHD, accompanied by the induction of transplantation tolerance and re-establishment of selftolerance with allogeneic mixed chimerism. ${ }^{31-33}$

\section{Mechanistic aspects for HSCT}

Currently, the most favored theory to support treatment with HSCT for autoimmune disease is that the reconstitution of the immune system from stem cells represents a recapitulation of ontogenesis and may be accompanied by the induction of self-tolerance from immune ablation and hematopoietic stem cells.

Potent immunosuppressive treatments with chemotherapy or TBI regimens can eliminate autoreactive memory B cells and T cells, thus "resetting" the immune system, that is, the elimination of T and/or B cell repertoires allows the patient's immune system to "start from scratch" and regenerate normally. The function of pathogenic and new developing $\mathrm{T}$ cell clones may be altered or immunomodulated by the conditioning and hematopoietic stem cells. For example, a study investigated qualitative immunologic changes that are responsible for the induction of immune tolerance by autologous HSCT in patients with juvenile idiopathic RA undergoing autologous HSCT. The study demonstrated the rapid restoration of the frequency of FoxP3 expressing CD4+CD25 $5^{\text {bright }}$ regulatory $\mathrm{T}$ cells from severely reduced numbers before HSCT to normal levels after HSCT, and a renewed thymopoiesis of naïve mRNA FoxP3 expressing CD4+CD25+ regulatory $T$ cells subsequently optimized the regulatory $\mathrm{T}$ cells repertoire and sustained the remission. ${ }^{34}$ Alternative mechanisms involved in HSCT may include intrathymic deletion (or tolerance) of newly developing autoreactive T cells, anergy, and deletion of peripheral auto-/ allo reactive $\mathrm{T}$ cells, tolerization of $\mathrm{B}$ cells induction through mixed allogeneic chimerism, and B lymphoablation. ${ }^{35}$

\section{Patient selection for HSCT}

In general, the indication for HSCT in patients with SSc follows the consensus guidelines "life or organ threatening autoimmune diseases refractory to conventional therapy and with sufficient reversible pathology to allow a decent quality of life after cessation of inflammation", in considering the morbidity and mortality associated with HSCT. ${ }^{36}$ In November 2002, a meeting was held in Florence, Italy aiming to analyze existing data from patients transplanted for autoimmune disorders and to propose a safe approach to these patients in relation to cardiotoxicity. Cardiac assessment was considered a high priority in cyclophosphamide-treated SSc. ${ }^{37}$ A modification of the stepped approach to cardiac assessment in patients with SSc and MS, proposed in 2004, seems appropriate for all patients undergoing HSCT. ${ }^{38}$

A careful and thorough cardiac and pulmonary assessment prior to HSCT should be performed including a standard 12-lead ECG, a trans-thoracic echocardiograph, $24 \mathrm{~h}$ Holter monitor, BNP or NT-proBNP and cardiac troponin I or T, coronary artery angiography or right heart catheterization if coronary artery disease or pulmonary hypertension are suspected, pulmonary function test, and thoracic highresolution computer tomography (HRCT). The specific clinical features of patients with SSc were associated with potential toxicity in phase I/II stem cell studies. For example, patients with a mean pulmonary artery pressure above $50 \mathrm{mmHg}$ by right heart catheterization or an ejection fraction below $40 \%$ tended not to tolerate sepsis with neutropenic fever, which induces a hyperdynamic cardiac output. Additionally, patients with SSc-related cardiac or pulmonary disease are prone to deteriorate, due to a combination of drug-induced organ toxicity and volume overload seen during the mobilization stage and conditioning. ${ }^{36}$ In patients with SSc, any reduction in ejection fraction is likely to be associated also with significant diastolic dysfunction. 
BNP or NT-proBNP is a more reliable test for screening patients for elevated filling pressures. An NT-proBNP level of $350 \mathrm{pg} / \mathrm{mL}$ has been identified as associated with an increased risk during HSCT. A level above $250 \mathrm{pg} / \mathrm{mL}$ has been identified as being associated with an increased mortality in patients with SSc-associated pulmonary artery hypertension. ${ }^{38}$ Furthermore, in patients prone to low-level myocardial injury, cardiac troponin (I or T) assays will detect patients in whom the probability of unforeseen cardiac events is greater. Therefore, echocardiography, and Holter monitoring, BNP or NT-proBNP and cardiac troponin I or T, and coronary angiography or right cardiac catheterization are recommended in patients with SSc prior to undergoing a HSCT.

\section{Mobilization of hematopoietic stem cells}

The most common peripheral blood stem cell (PBSC) mobilization regimen are single-agent granulocytes colony-stimulating factor (G-CSF) or cyclophosphamide and G-CSF, based on methods established for patients with non-autoimmune disorders. ${ }^{39}$ Flares of autoimmune diseases like RA and MS have occurred in patients taking G-CSF as a single regimen for mobilization, presented with transient swollen and tender joints in RA and serious and irreversible neurological deterioration in MS. ${ }^{40,41}$ The only complication of G-CSF PBSC mobilization in patients with SSc was transient telangiectasias that spontaneously resolve. Patients with SSc with cardiac and/or pulmonary involvement undergoing PBSC with high-dose cyclophosphamide $\left(4.0 \mathrm{~g} / \mathrm{m}^{2}\right)$ may have cardiac and/or pulmonary complications. ${ }^{40}$ After collection of progenitor cells, many groups perform ex vivo lymphocyte depletion. Aggressive lymphocyte depletion may increase the risk of post-transplantation opportunistic infections such as cytomegalovirus, fungemia, Pneumocystis carinii pneumonia, or Epstein-Barr virus post-transplantation lymphoproliferative disease (PTLD). ${ }^{39}$ The PBSC method, therefore, should be individualized for the disease and organ involved.

\section{Conditioning regimens}

Cyclophosphamide, cyclophosphamide I antithymocyte globulin (ATG), and cyclophosphamide/TBI/ATG have been commonly used as conditioning regimens for SSc. ${ }^{42-44}$ As mentioned before, high-dose cyclophosphamide is associated with high cardiopulmonary mortality in patients with SSc. ${ }^{40}$ TBI without lung shielding has been associated with lethal pulmonary deterioration in patients with pulmonary scleroderma. ${ }^{44}$ When using high-dose
(40-70 Gy) localized radiation to treat cancer in patients with SSc, radiation-related injury may extend beyond the radiation field and cause death in approximately a third of patients and/or severe fibrosis in areas overlapping the radiation field. ${ }^{45}$ When using low-dose (18 Gy) radiation, patients with SSc may develop radiation-related toxicities that are difficult to distinguish from disease exacerbation. ${ }^{46}$ The TBI-related lung injury may be lessened if partial lung shielding is used. One possible mechanism of radiationrelated injury is that radiation may be synergistic or additive to ongoing scleroderma-related vascular injury and tissue fibrosis. ${ }^{47}$ The histological features of late radiation injury are similar to $\mathrm{SSc}$, including a vasculopathy with loss of capillaries, telangiectasia, and excessive collagen deposition. ${ }^{48}$ Furthermore, because high-dose rabbit ATG has been reported to be associated with lethal PTLD, lower-dose rabbit ATG or the use of horse ATG are recommended. ${ }^{49}$ All patients should be warned of infertility, late toxicities like cataracts, or late malignancies from TBI and/or cyclophosphamide. ${ }^{50}$ Again, individualized conditioning regimens need be designed to decrease the risk of organ damage and infection, and therefore minimize regimen-related morbidity and mortality.

\section{Clinical trials and outcome Autologous HSCT}

Early phase I/II studies reported improved skin scores and activities of daily living but unchanged renal, cardiac, and pulmonary function. However, with intensive immunosuppressive regimens, these studies showed significantly high treatment-related mortality (TRM). In the first 41 transplanted patients with SSc after a median of 12 months of follow-up, as reported to the EBMT/EULAR database, an improvement of $25 \%$ or more in the skin score (measured by the modified Rodnan method) was seen in $70 \%$ of the patients, with a TRM observed initially at $17 \%$, and later at $12.5 \%$ when an additional 24 patients were recruited. ${ }^{20}$ Several protocols have been used; peripheral blood stem cell mobilization has been performed with cyclophosphamide alone or combined with granulocyte colony stimulation factor. Seven conditioning regimens have been used including cyclophosphamide \pm antithymocyte globulin \pm total body irradiation. A long-term follow-up of this cohort reported a significant drop in skin score of $>25 \%$ of initial values in $79 \%$ patients at 2 years and $60 \%$ patients at 3 years after HSCT. Complete and partial remission was observed in two-thirds of the patients up to 3 years after HSCT. The overall TRM was of $8.7 \% .^{21}$ The reduced TRM contributed 
to more careful patient selection by careful cardiac and pulmonary function evaluation.

A US multicenter pilot study of 19 patients with SSc using a regimen of cyclophosphamide $120 \mathrm{mg} / \mathrm{kg}$ body weight, TBI 8 Gy, and equine ATG $90 \mathrm{mg} / \mathrm{kg}$ body weight and a CD 34+ selected graft product, showed a sustained improvement in skin scores and overall function in 12 patients at a median follow-up of 14.7 months. Initially, 2/8 (25\%) patients died of TBI-related interstitial pneumonitis. After amending the protocol with lung shielding, 2 of the last 11 patients died, 1 from Epstein-Barr virus infection and 1 from renal failure. Pulmonary function in 4/9 (44\%) patients remained clinically unchanged (less than $15 \%$ variation), but declined in 5/9 (56\%) patients. ${ }^{51}$ A long-term follow-up (median 4 years) of the US multicenter pilot study showed marked clinical improvement in skin and overall function (modified Health Assessment Questionnaire Disability index). Biopsies confirmed a statistically decrease of dermal fibrosis compared with baseline $(P<0.001)$. Lung, heart, and kidney remained clinically stable. The overall TRM was of $23.5 \%(8 / 34) .{ }^{52}$ These data suggest that a myeloablative regimen containing TBI was associated with significant TBI-related pulmonary toxicity. A French cohort of 12 patients with refractory SSc was reported using a regimen of cyclophosphamide $\left(4 \mathrm{~g} / \mathrm{m}^{2}\right)$ and recombinant human granulocyte colony-stimulating factor ( $5 \mu \mathrm{g} / \mathrm{kg} /$ day $)$ with positive CD 34+ selection, conditioning used cyclophosphamide $(200 \mathrm{mg} / \mathrm{kg})$ or melphalan $\left(140 \mathrm{mg} / \mathrm{m}^{2}\right)$ according to cardiac function. After 18 months (range 1-26), 8 out of 11 patients have shown major or partial response, while 5 relapsed within 1 year; there was 1 procedure-related death and 3 resulting from disease progression. ${ }^{53}$ Recently, a phase I non-myeloablative (without TBI) autologous HSCT study $(n=10)$ reported sustained improvement in skin score and stabilization in cardiac, pulmonary, and renal function after a median follow-up of 25.5 months. The overall TRM was 0 . The overall and progression-free survival rates were $90 \%$ and $70 \%$ respectively ${ }^{54}$ Furthermore, a long-term follow-up study with 26 patients with severe SSc in the Netherlands and France using a non-myeloablative conditioning regimen showed sustained improvement of skin thickening and stabilization of organ function after a median follow-up of 5.3 years. The overall survival rate at 5 years was $96.2 \%$ and at 7 years $84.8 \% .^{55}$ The data from these two studies suggest that a non-myeloablative conditioning regimen may result in improved skin flexibility similar to a myeloablative TBI-containing regimen, but without the toxicity and risks associated with TBI.
In terms of the efficacy of HSCT in SSc, most studies have demonstrated softening skin which paralleled capillary regeneration, reduced transcription of profibrotic genes, and remodeling of the vasculopathy and fibrosis. ${ }^{55-57}$ For example, a recent study showed improvement in microcirculation measured by nail fold videocapillaroscopy (NVC) in patients with SSc. At 3 months after HSCT, the NVC pattern changed from "late pattern", as avascular areas and vascular architecture disorganization, into "active pattern", as frequent giant capillaries and active angiogenesis. ${ }^{57}$ One study reported using local injection of CD 34+ cells and mononuclear cells for ischemic skin ulcers in hands and lower extremities in patients with SSc, and showed rapid beneficial effect on vascular symptoms resulting in ulcer healing. The therapeutic efficacy was associated with restoration of endothelial function, augmentation of microcirculatory blood flow, and significant increase in angiogenesis. ${ }^{58} \mathrm{~A}$ single-institution pilot study reported a significant and rapid decrease of the extent of pulmonary fibrosis associated with SSc observed on HRCT in 9 patients with severe diffuse SSc 6 months after autologous HSCT. The early treatment effects of HSCT on the extent of pulmonary fibrosis decreased over time and were transient in some patients after long-term follow up. ${ }^{59}$ Additionally, a new study demonstrated immunological reconstitution obtained from suppression of thymic function after autologous HSCT in 10 patients with SSc, assessed by quantification of signal joint $\mathrm{T}$ cell receptor rearrangement excision circles (sjTREC). ${ }^{60}$

The protocols of the ASTIS and SCOT trials are similar in their selection criteria, primary outcome and control arms, but differs in the conditioning regimens. ASTIS utilizes cyclophosphamide $200 \mathrm{mg} / \mathrm{kg}$ body weight and rabbit ATG, and SCOT uses cyclophosphamide $129 \mathrm{mg} / \mathrm{kg}$ body weight, equine ATG, and radiation of $800 \mathrm{cGy}$ (with shielding of the lungs and kidney). ${ }^{61}$ The ASTIS trial was launched in 2001. As of June 2008, 122 patients have been randomized in 25 centers from 10 countries and allocated to either high-dose immunoablation followed by autologous stem cell transplantation (66 patients) or pulse-therapy cyclophosphamide iv (56 patients). The aim of the trial is to compare the safety and efficacy of HSCT versus pulsed cyclophosphamide therapy in patients with severe SSc. The SCOT trial was planed to recruit 226 patients with diffuse $\mathrm{SSc}$, randomly assigned in a 1:1 ratio to either high-dose immunosuppressive therapy with autologous stem cell transplantation or monthly iv pulse cyclophosphamide for 12 months. All subjects will be followed up to 44 months after randomization. The primary study endpoint for the SCOT study is "event-free" survival at 
44 months after randomization. To date, over 4000 samples from 50 randomized subjects have been collected from baseline and to time points through year 5 after randomization (www.sclerodermatrial.org). Both trials include extensive mechanistic studies relating to immune reconstitution, skin biopsy immunohistology, collagen and vascular remodeling, bronchoalveolar lavage cellular components, and HRCT lung changes. ${ }^{61}$ These clinical trials will determine whether HSCT yields sufficient clinical benefit to warrant further trials to enhance its efficacy and/or improve safety.

\section{Allogeneic HSCT}

The concept of allogeneic HSCT is total reconstitution of the immune cells with donor cells in order to eliminate autoreactive immune cells. However, myeloablative conditioning and GVHD as a known complication carry a significant morbidity and mortality in patients with SSc. Four cases were reported, all of whom received a reduced intensity non-myeloablative HSCT. ${ }^{62-64}$ Three cases obtained successful responses (dramatically decreased skin score and stable pulmonary function) and 2 cases reported GVHD that developed in relation to allogeneic HSCT, one of whom died of complications related to acute GVHD. A multidisciplinary consensus group published a guideline for allogeneic HSCT in autoimmune diseases. ${ }^{65}$

\section{Multipotent mesenchymal stromal cells (MSCs)}

The plastic-adherent cells isolated from bone marrow and other sources have come to be widely known as multipotent MSCs, also referred as mesenchymal stem cells, although they are not true "stem cells", as the biological properties of the unfractionated cells do not meet accepted criteria of stem cell activities. MSCs are capable of differentiating in vitro and in vivo to different MSC lineages, including adipose, bone, cartilage, muscle, and myelosupportive stroma. MSCs can be isolated from bone marrow, skeletal muscle, adipose tissue, synovial membranes, and other connective tissues of human adults as well as cord blood and placental products. ${ }^{66}$ In vitro and in vivo studies from animal models and human tissues suggest that MSCs may possess antiproliferative, anti-inflammatory, and immunosuppressive properties. The first disease in which the therapeutic potential of MSCs was addressed was an EAE model of MS. When injected in mice with chronic EAE induced by the MOG 35-55 peptide, MSCs showed a strong migratory potential to the white matter. The clinical course of EAE was significantly improved in animals treated with purified MSCs after both intracerebroventricular and intravenous administration. ${ }^{67}$ The bone marrow-derived MSCs have been shown to suppress the proliferation of stimulated $\mathrm{T}$ lymphocytes in patients with autoimmune diseases including systemic lupus erythematosus, RA, dermatomyositis, or SSc. ${ }^{68} \mathrm{MSCs}$, therefore may be a potential treatment option in autoimmune diseases. ${ }^{61}$ Autologous bone marrow-derived MSCs in SSc patients have been shown to be normal with respect to proliferation, clonogenicity and differentiation to bone and fat. ${ }^{71}$ However, one study has shown defective differentiation into endothelial precursors in bone marrow-derived MSCs from SSc patients, ${ }^{70}$ which should be considered when choosing autologous or allogeneic MSCs sources for scleroderma treatment.

Several phase I and II trials have showed no acute or longterm adverse events after ex vivo expanded allogeneic MSCs infused to promote hematopoietic recovery from autologous or allogeneic HSCT and to treat patients with osteogenesis imperfecta. ${ }^{71-76}$ Two cases reported successful treatment from infusion of in vitro expanded MSCs in patients with steroidresistant severe acute GVHD, a condition sharing similarities with SSc. ${ }^{77,78}$ One case report showed improvement in a patient with severe progressive SSc after transplantation of MSCs from an allogeneic haploidentical-related donor. ${ }^{79}$ In a multicenter, phase II trial of MSCs for treatment of steroid-resistant severe acute GVHD, 55 patients received ex vivo expanded MSCs. Of these patients, 39/55 (71\%) had either complete or partial responses, none had acute side effects during or immediately after infusion of MSCs, $3 / 55(7 \%)$ had recurrent malignant disease, and 1 developed de novo acute myeloid leukemia of recipient origin. ${ }^{80}$ The data suggested that MSCs derived from bone marrow might be a safe and effective treatment for patients with severe acute GVHD who do not respond to corticosteroid and other immunosuppressive therapies.

Few publications on the results of using MSCs in human autoimmune disease are available. Phase I/II clinical trials are underway in Crohn's disease and MS and are being planned for systemic lupus erythematosus, SSc, vasculitis and other autoimmune diseases. ${ }^{81}$ Coordinated by the EBMT, an international interdisciplinary registry of MSC-treated patients has been launched to allow uniform collection of long-term safety data. ${ }^{82}$

\section{Conclusion}

Systemic sclerosis is an autoimmune connective tissue disorder of unknown causes characterized by humoral and cellular immune dysregulation, microvasculopathy, and progressive cutaneous and visceral fibrosis. Severe diffuse 
SSc is associated with a mortality of $40 \%$ to $50 \%$ within 5 years. In the past decade, HSCT has been explored for the treatment for autoimmune diseases including SSc. Studies in animal models showed that the transfer of hematopoietic stem cells may "reset" the immune reconstitution and induce the self-tolerance of autoreactive $\mathrm{T}$ and $\mathrm{B}$ cells. Phase I/II clinical trials in autologous HSCT for patients with SSc have shown a satisfactory benefit, including long-term improvement in skin thickening and stability of visceral organ involvement. The treatment-related mortality decreased from $17 \%$ to $8.7 \%$ with careful patient selection. Two ongoing prospective, randomized phase III trials (ASTIS and SCOT) will help to determine the efficacy and safety profile in patients with severe SSc after autologous HSCT. Only a few cases of successful responses have been reported with the use of allogeneic HSCT in SSc patients, but treatment-related complication like GHVD have been frequent. Recently, multipotent MSCs have shown promise as an antiproliferative, anti-inflammatory and immunosuppressive agent in phase II trials for patients with severe steroid-resistant acute GVHD, and may potentially open a new era of therapy for SSc.

\section{Disclosures}

The authors declare no conflicts of interest.

\section{References}

1. Badea I, Taylor M, Rosenberg A, Foldvari. Pathogenesis and therapeutic approaches for improved topical treatment in localized scleroderma and systemic sclerosis. Rheumatology. 2009;48:213-221.

2. Steen VD, Medsger TA. Changes in causes of death in systemic sclerosis, 1972-2002. Ann Rheum Dis. 2007;66:940-944.

3. Clements PJ, Lachenbruch PA, Ng SC, et al. Skin score. A semiquantitative measure of cutaneous involvement that improves prediction of prognosis in systemic sclerosis. Arthritis Rheum. 1990;33:1256-1263.

4. Aitman RD, Medsger TA, Bloch DA, Michel BA. Predictor of survival in systemic sclerosis (scleroderma). Arthritis Rheum. 1991;34:403-413.

5. Jacobsen S, Halberg P, Ullman S. Mortality and causes of death of 344 Danish patients with systemic sclerosis (scleroderma). Br J Rheumatol. 1998;37:750-755.

6. Bryan C, Howard Y, Brennan P, Black C, et al. Survival following the onset of scleroderma: results from a retrospective inception cohort study of the UK patients population. Br J Rheumatol. 1996;35:1122-1126.

7. Abu-Shakra M, Lee P. Mortality in systemic sclerosis: a comparison with the general population. J Rheumatol. 1995;22:2100-2102.

8. Jimenez SA, Derk CT. Following the molecular pathways towards an understanding of systemic sclerosis. Ann Intern Med. 2004;140:1-15.

9. Abraham1 DJ, Krieg T, Distler J, et al. Overview of pathogenesis of systemic sclerosis. Rheumatology. 2009;48:iii3-iii7.

10. Tashkin DP, Elashoff R, Clements PJ, Roth MD, Furst DE, Silver RM, et al. Effect of 1-year treatment with cyclophosphamide on outcomes at 2 years in scleroderma lung disease. Am J Respir Crit Care Med. 2007; 176:1026-1034.

11. Liossis SNC, Bounas A, Andonopoulos AP. Mycophenolate mofetil as first-line treatment improves clinically evident early scleroderma lung disease. Rheumatology. 2006;45:1005-1008.
12. Swigris JJ, Olson AL, Fischer A, et al. Mycophenolate mofetil is safe, well tolerated, and preserves lunf function in patients with connective tissue disease-related interstitial lung disease. Chest. 2006; 130:30-36.

13. Kowal-Bielecka O, Landewe R, Avouac J, et al. EULAR recommendations for the treatment of systemic sclerosis: a report from the EULAR Scleroderma Trials and Research group (EUSTAR). Ann Rheum Dis. 2009;68:620-628.

14. Bournia VKK, Vlachoyiannopoulos PG, Selmi C, et al. Recent advances in the treatment of systemic sclerosis. Clinic Rev Allerg Immunol. 2009;36:176-200.

15. Hemmatazad H, Rodrigues HM, Maurer B, et al. Histone deacetylase 7, a potential target for the antifibrotic treatment of systemic sclerosis. Arthritis Rheum. 2009;60:1519-1529.

16. Sykes M, Nikolic B. Treatment of severe autoimmune disease by stem cell transplantation. Nature. 2005;435:620-627.

17. van Bekkum DW. Preclinical experiments. Best Pract Res Clin Haematol. 2004;17:201-222.

18. Nelson JL, Torrez R, Louie FM, et al. Pre-existing autoimmune disease in patients with long-term survival after allogeneic bone marrow transplantation. J Rheumtol. 1997;Suppl 48:23-29.

19. Tamm M, Gratwohl A, Tyndall A, et al. Autologous hematopoietic stem cell transplantation in a patient with severe pulmonary hypertension complicating connective tissue disease. Ann Rheum Dis. 1996;55: 779-780.

20. Binks M, Passweg JR, Furst D, et al. Phase I/II trial of autologous stem cell transplantation in systemic sclerosis: procedure related mortality and impact on skin disease. Ann Rheum Dis. 2001;60:577-584.

21. Farge D, Passweg JR, van Laar JM, et al. Autologous stem cell transplantation in the treatment of systemic sclerosis: report from the EBMT/EULAR Registry. Ann Rheum Dis. 2004;63:974-981.

22. Van Laar JM, Farge D, Tyndall A. Autologous Stem Cell Transplantation International Scleroderma (ASTIS) trial: hope on the horizon for patients with severe systemic sclerosis. Ann Rheum Dis. 2005;64:1515.

23. van Bekkum DW: Review: BMT in experimental autoimmune diseases. Bone Marrow Transplant. 1993;1:183-187.

24. Ikehara S, Kawamura M, Takao F, et al. Organ-specific and systemic autoimmune diseases originate from defects in hematopoietic stem cells. Proc Natl Acad Sci U S A. 1990;87:8341-8344.

25. van Bekkum DW. Conditioning regimens for the treatment of experimental arthritis with autologous bone marrow transplantation. Bone Marrow Transplant. 2000;25:357-364.

26. van Gelder M, van Bekkum DW. Effective treatment of relapsing experimental autoimmune encephalomyelitis with psudoautologous bone marrow transplantation. Bone Marrow Transplant. 1996;18: 1029-1034.

27. van Gelder M, van Bekkum DW. Treatment of relapsing experimental autoimmune encephalomyelitis with largely MHC-matched allogeneic bone marrow transplantation. Transplantation. 1996;62:810-818.

28. Slavin S, Nagler A, Varadi G, et al. Graft vs autoimmunity following allogeneic non-myeloabalative blood stem cell transplantation in a patient with chronic myelogenous leukemia and severe systemic psoriasis and psoriatic polyarthritis. Exp Hematol. 2000;28:853-857.

29. Burt RK, Traynor. Hematopoietic stem cell therapy of autoimmune diseases. Curr Opin Hematol. 1998;5:472-477.

30. Sykes M, Nikolic B. Treatment of severe autoimmune disease by stem-cell transplantation. Nature. 2005;435:620-627.

31. Prigozhina T, Gurevitch O, Slavin S. Non-myeloablative conditioning to induce tolerance after allogeneic bone marrow transplantation in mice. Exp Hematol. 1999;27:1503-1510.

32. Loy Y, Oyama Y, Statkute L, et al. Non-myeloablative allogeneic hematopoietic stem cell transplantation for severe systemic sclerosis: graft-versus-autoimmunity without graft-versus-host disease? Bone Marrow Tranplant. 2007;39:435-437.

33. Burt RK, Oyama Y, Verda L, et al. Induction of remission of severe and refractory rheumatoid arthritis by allogeneic mixed chimerism. Arthritis Rheum. 2004;50:2466-2470. 
34. de Kleer I, Vastert B, Klein M, et al. Autologous stem cell transplantation for autoimmunity induces immunologic self-tolerance by reprogramming autoreactive $\mathrm{T}$ cells and restoring the $\mathrm{CD} 4+\mathrm{CD} 25+$ immune regulatory network. Blood. 2006;107:1696-1702.

35. St Clair EW, Tedder TF. New prospects for autoimmune disease therapy: B cells on deathwatch. Arthritis Rheum. 2006;54:1-9.

36. Tyndall A, Furst DE. Adult stem cell treatment of scleroderma. Curr Opin Rheumatol. 2007;19:604-610.

37. Saccardi R, Tyndall A, Coghlan G, et al. Consensus statement concerning cardiotoxicity occurring during hematopoietic stem cell transplantation in the treatment of autoimmune diseases, with special reference to systemic sclerosis and multiple sclerosis. Bone Marrow Transplant. 2004:34:877-881.

38. Coghlan JG, Handler CE, Kottaridis PD. Cardiac assessment of patients for hematopoietic stem cell transplantation. Best Pract Res Clin Haematol. 2007;20:247-263.

39. Burt RK, Slavin S, Burns WH, et al. Induction of tolerance in autoimmune diseases by hematopoietic stem cell transplantation: getting closer to a cure. Blood. 220;99:768-784.

40. Burt RK, Fassas A, Snowden J, et al. Collection of hematopoietic stem cells from patients with autoimmune diseases. Bone Marrow Transplant. 2001;28:1-12.

41. Openshaw H, Stuve O, Antel JP, et al. Multiple sclerosis flare associated with recombinant granulocyte colony-stimulating factor. Neurology. 2000;54:2147-2150.

42. Tyndall A, Black C, Finkle J, et al. Treatment of systemic sclerosis with autologous hematopoietic stem cell. Lancet. 1997;349:254.

43. Rosen O, Thiel A, Massenkeil G, et al. Autologous stem-cell transplantation in refractory autoimmune disease after in vivo immunoablation and ex vivo depletion of mononuclear cells. Arthritis Res. 2000;2:327-336.

44. McSweeney PA, Furst DE, Storek J, et al. High dose immune suppressive therapy (HDIT) using total body irradiation (TBI) cyclophosphamide (CY) and ATG with autologous CD 34+ selected peripheral blood stem cell (PBSC) rescue as treatment for severe systemic sclerosis. [abstract]. Blood. 1998;92 Suppl:285.

45. Chen AM, bedian E, Haffty BG. Breast-conserving therapy in the setting of collagen vascular disease. Cancer J. 2001;7:480-491.

46. O'Dell JR, Steigerward JC, Kennaugh RC, et al. Lack of clinical benefit after treatment of systemic sclerosis with total lymphoid irradiation. J Rheumatol. 1989;16:1050-1054.

47. Burt RK, Kallunian K, Patel D, et al. The rational behind autologous autoimmune hematopoietic stem cell transplant conditioning regimens: concerns over the use of total body irradiation in systemic sclerosis. Bone Marrow Transplant. 2004;34:745-751.

48. Law MP. Radiation-induced vascular injury and its relation to late effects in normal tissues. In: Lett J, Adler H, eds. Advances in Radiation Biology. New York: Academic Press; 1981;9:37-73.

49. Nash RA, Dansey R, Storec J, et al. Epstein-Barr virus (EBVassociated post-transplantation lymphoproliferative disorder (PTLD) after high-dose immunosuppressive therapy (HDIT) and autologous CD34-selected stem cell transplantation (SCT) for severe autoimmune diseases. [abstract]. Blood. 2000;96 Suppl:406a.

50. Curtis RE, Rowlings PA, Deeg HJ, et al. Solid cancers after bone marrow transplantation. $N$ Engl J Med. 1997;336:897-904.

51. McSweeney PA, Nash RA, Sullivan KM, et al. High-dose immunosuppressive therapy for several systemic sclerosis: initial outcomes. Blood. 2002;100:1602-1610.

52. Nash RA, McSweeney PA, Crofford LJ, et al. High-dose immunosuppressive therapy and autologous hematopoietic cell transplantation for several systemic sclerosis: long-term follow-up of the US multicenter pilot study. Blood. 2007;110:1388-1396.

53. Farge D, Marolleau JP, Zohar S, et al. Autologous bone marrow transplantation in the treatment of refractory systemic sclerosis: early results from a French multicentre phase I-II study. Br J Haematol. 2002;119:26-39.
54. Oyama Y, Barr WG, Statkute L, et al. Autologous non-myeloablative hematopoietic stem cell transplantation in patients with systemic sclerosis. Bone Marrow Transplant. 2007;40:549-555.

55. Vonk MC, Marjanovic Z, van den Hoogen FHJ, et al. Long-term follow-up results after autologous hematopoietic stem cell transplantation for severe systemic sclerosis. Ann Rheum Dis. 2008;67:98-104.

56. Fleming JN, Nash RA, McLeod DO, et al. Capillary regeneration in scleroderma: stem cell therapy reverses phenotype? PLoS One. 2008;1: e1452.

57. Miniati I, Guiduccci S, Conforti ML, et al. Autologous stem cell transplantation improves microcirculation in systemic sclerosis. Ann Rheum Dis. 2009;68:94-98.

58. Nevskaya T, Ananieva L, Bykovskaia S, et al. Autologous cell implantation as a novel therapeutic intervention for ischemic digits in systemic sclerosis. Rheumatology. 2009;48:61-64.

59. Launay D, Marjanovic Z, de Bazelaire C, et al. Autologous hematopoietic stem cell transplant in systemic sclerosis: quantitative high resolution computed tomography of the chest scoring. J Rheumatol. 2009;36:1460-1463.

60. Bohgaki T, Atsumi T, Bohgaki M, et al. Immunological reconstitution after autologous hematopoietic stem cell transplantation in patients with systemic sclerosis: relationship between clinical benefits and intensity of immunosuppression. J Rheumatol. 2009;36:1240-1248.

61. van Laar JM, and Tyndall A. Cellular therapy of systemic sclerosis. Curr Rheum Rep. 2008;10:189-194.

62. Nash RA, McSweeney PA, Nelson JL, et al. Allogeneic marrow transplantation in a patient with severe systemic sclerosis: resolution of dermal fibrosis. Arthritis Rheum. 2006;54:1982-1886.

63. Khorshid O, Hosing C, Bibawi S, et al. Nonmyeloablative stem cell transplant $\mathrm{n}$ a patient with advanced systemic sclerosis and systemic lupus erythematosus. J Rheumatol. 2004;31:2513-2516.

64. Shiratsuchi M, Motomura S, Abe Y, et al. Long-term follow-up after nonmyeloablative allogeneic hematopoietic stem cell transplantation for systemic sclerosis. Clin Rheumatol. 2008;27:1207-1209.

65. Griffith LM, Pavletic SZ, Tyndall A, et al. Target populations in allogeneic hematopoietic cell transplantation for autoimmune diseases - a workshop accompanying: cellular therapy for treatment of autoimmune diseases, basic science and clinical studies, including new developments in hematopoietic and mesenchymal stem cell therapy. Biol Blood Marrow Transplant. 2006;12:688-690.

66. Tyndall A, Gratwohl A. Adult stem cell transplantation in autoimmune disease. Curr Opin Hematol. 2009;16:285-291.

67. Karussis D, Kassis I. The potential use of stem cells in multiple sclerosis: An overview of the preclinical experience. Clin Neurol Neurosurg. 2008;110:889-896.

68. Bocelli-Tyndall C, Bracci L, Spagnoli G, et al. Bone marrow mesenchymal stromal cells (BM-MSCs) from healthy donors and autoimmune disease patients reduce the proliferation of autologousand allogeneic-stimulated lymphocytes in vitro. Rheumatology. 2007;46:403-408.

69. Larghero J, Farge D, Braccini A, et al. Phenotypical and functional characteristics of in vitro expanded bone marrow mesenchymal stem cells from patients with systemic sclerosis. Ann Rheum Dis. 2008; 67:443-449.

70. Cipriani P, Guiducci S, Miniati I, et al. Impairment of endothelial cell differentiation from bone marrow-derived mesenchymal stem cells. Arthritis Rheum. 2007;56:1994-2004.

71. Horwitz EM, Gordon PL, Koo WK, et al. Isolated allogeneic bone marrow-derived mesenchymal cells engraft and stimulate growth in children with osteogenesis imperfecta: implications for cell therapy of bone. Proc Natl Acad Sci U SA. 2002;99:8932-8937.

72. Lazarus HM, Haynesworth SE, Gerson SL, Rosenthal NS, Caplan AI. Ex vivo expansion and subsequent infusion of human bone marrowderived stromal progenitor cells (mesenchymal progenitor cells): implications for therapeutic use. Bone Marrow Transplant. 1995;16: $557-564$. 
73. Lazarus HM, Koc ON, Devine SM, et al. Cotransplantation of HLA-identical sibling culture-expanded mesenchymal stem cells and hematopoietic stem cells in hematologic malignancy patients. Biol Blood Marrow Transplant. 2005;11:389-398.

74. Koc ON, Gerson SL, Cooper BW, et al. Rapid hematopoietic recovery after coinfusion of autologous-blood stem cells and culture-expanded marrow mesenchymal stem cells in advanced breast cancer patients receiving high-dose chemotherapy. J Clin Oncol. 2000;18:307-316.

75. Ball LM, Bernardo ME, Roelofs H, et al. Cotransplantation of ex vivo expanded mesenchymal stem cells accelerates lymphocyte recovery and may reduce the risk of graft failure in haploidentical hematopoietic stem-cell transplantation. Blood. 2007;110:2764-2767.

76. Le Blanc K, Samuelsson H, Gustafsson B, et al. Transplantation of mesenchymal stem cells to enhance engraftment of hematopoietic stem cells. Leukemia. 2007;21:1733-1738.

77. Le Blanc K, Rasmusson I, Sundberg B, et al. Treatment of severe acute graft-versus-host disease with third party haploidentical mesenchymal stem cells. Lancet. 2004;363:1439-1441.
78. Ringden O, Uzunel M, Rasmusson I, et al. Mesenchymal stem cells for treatment of therapy-resistant graft-versus-host disease. Transplantation. 2006;81:1390-1397.

79. Christopeit M, Schendel M, Föll J, et al. Marked improvement of severe progressive systemic sclerosis after transplantation of mesenchymal stem cells from an allogeneic haploidentical-related donor mediated by ligation of CD 137L. Leukemia. 2008;22:1062-1064.

80. Le Blanc K, Frassoni F, Ball L, et al. Mesenchymal stem cells for treatment of steroid-resistant, severe, acute graft-versus-host disease a phase II study. Lancet. 2008;371:1579-1586.

81. Tyndall A, Uccelli A. Multipotent mesenchymal stromal cells for autoimmune diseases: teaching new dogs old tricks. Bone Marrow Transplant. 2009;43:821-828.

82. Le Blanc K, Fibbe W. A new cell therapy registry coordinated by the Europe Group for Blood and Marrow Transplantation (EBMT). Bone Marrow Transplant. 2008;41:319.
Stem Cells and Cloning: Advances and Applications

\section{Publish your work in this journal}

Stem Cells and Cloning: Advances and Applications is an international, peer-reviewed, open access journal. Areas of interest in stem cell research include: Embryonic cell stems; Adult stem cells; Blastocysts; Cordblood stem cells; Stem cell transformation and culture; Therapeutic cloning; Umbilical cord blood and bone marrow cells; Laboratory,

\section{Dovepress}

animal and human therapeutic studies; Philosophical and ethical issues related to stem cell research. This journal is indexed on CAS. The manuscript management system is completely online and includes a quick and fair peer-review system. Visit http://www.dovepress.com/ testimonials.php to read real quotes from published authors.

Submit your manuscript here: http://www.dovepress.com/stem-cells-and-cloning-advances-and-applications-journal 